\title{
Nutrition Transition in Africa: Consequences and Opportunities
}

\author{
Teresia Mbogori ${ }^{1}$ and Winnie Mucherah²
}

\begin{abstract}
Nutrition transition, defined as a shift in dietary patterns and energy expenditure, is a major concern worldwide and especially in low- and middle-income countries. Nutrition transition is linked to an increased prevalence of metabolic disorders and non-communicable diseases such as obesity, diabetes and cardiovascular diseases. In regions such as the sub-Saharan Africa, prevalence of overweight and obesity has steadily increased in the recent years despite the high prevalence of hunger and malnutrition. Factors that have contributed to nutrition transition include urbanization, socio-economic developments and technological advancements. Food consumption in some households has shifted to diets rich in fats and oils, calorie-based sweeteners, and animal-based products high in saturated fats (diets commonly referred to as "western diets"), from traditional African diets based on legumes, whole grain products and traditional vegetables. Opportunities to slow down the effects of nutrition transition in Africa may exist through education and policy changes that are culturally sensitive.
\end{abstract}

Keywords: Nutrition transition, Health and development, Malnutrition, Traditional African diet

\section{Introduction}

Malnutrition, a condition that refers to deficiencies, excesses or imbalances in a person's intake of energy and/or nutrients, remains a major hindrance to the social and economic development of a country especially in Sub-Saharan Africa (Bain et al., 2013). Macronutrient and micronutrient malnutrition in women and children increases their vulnerability to infections which increases the levels of childhood and maternal mortality (Stein, 2010). Stunting due to chronic hunger is associated with inadequate cognitive development which reduces the learning abilities and productivity of the child later in life and leads to the vicious cycle of poverty and malnutrition (Vorster, 2010). Similarly, overweight and obesity causes an economic and social burden to the country due to high costs of its management (Allender \& Rayner, 2007). Many Sub-Saharan African countries are struggling with both undernutrition and overweight, also known as the double burden of malnutrition. This has been attributed to the rapid

Full listing of authors and contacts can be found at the end of this article. nutrition transition being witnessed all over the world and especially in developing countries.

Nutrition transition, defined as a shift in dietary patterns and energy expenditure, is a major concern worldwide and especially in low and middle-income countries (Popkin, 1994; Popkin, Adair, \& Ng, 2012). Nutrition transition in the Africa is linked to increased prevalence of metabolic disorders and non-communicable diseases such as obesity, diabetes and cardiovascular diseases (Bosu, 2015). In sub-Saharan Africa, prevalence of overweight and obesity has steadily increased in the recent years despite the high prevalence of hunger and malnutrition (Tzioumis, Kay, Bentley, \& Adair, 2016). Consumption of high energy dense foods such as soft drinks and deep fried foods has replaced the traditionally consumed foods that were high in whole grain cereals and vegetables in most African homes. In addition, improvement in infrastructure and economic status has reduced the duration and intensity of physical activity among children and adults (Steyn \& McHiza, 2014).

Published by the Global Insitutute of Transformative Education (http://www.gite.education) 
Several studies have reported on the extent and consequences of nutrition transition and the double burden of malnutrition in Africa (Abrahams, McHiza, \& Steyn, 2011; Steyn \& McHiza, 2014; Steyn, Nel, Parker, Ayah, \& Mbithe, 2012). Some of the main consequences include development of chronic diseases such as diabetes, high cholesterol levels and high blood pressure and cardiovascular diseases (Albala, Vio, Kain, \& Uauy, 2002). These consequences are of great impact especially on the health care systems in African countries as these countries are still struggling with maternal and childhood undernutrition and micronutrient deficiencies.

Childhood is a very critical period in the development of an individual. While nutrition transition affects all stages of development, infancy and childhood stages are more likely to experience a greater impact. Fortunately, it is easier to change or modify behaviors at young ages than it is to change behavior of adults. Most studies done on nutrition status in children in African countries mainly focus on increasing food intake to prevent undernutrition and very few studies investigate the changes in dietary patterns of the children that could lead to overweight and obesity later in life. Therefore, the purpose of this paper is to describe nutrition transition and highlight some of its consequences in children as well as to suggest some opportunities to mitigate the effects of nutrition transition within the African context.

\section{Nutrition Transition}

Nutrition transition was first described by Popkin (1994) as shifts in dietary patterns that are reflected through changes in body size and composition. Popkin proposed five patterns of nutrition transition which represent the different stages of dietary changes in a population. First pattern is referred to as "hunter gatherer" and it describes the diets consumed in the hunter gatherer period if human evolution. These diets were high in carbohydrate, fiber and low in saturated fat. Also, activity levels were high and obesity rates were very low. The second pattern is referred to as "famine" and it describes a period in time where there was food shortage that led to a decrease in dietary diversity and adequacy. Also, towards the end of this period agricultural revolution occurred and societies that were more civilized were able to feed their population. Although this stage mainly occurred in the 18th century in the developed countries, many places in sub-Saharan Africa are still dealing with famine today.
"Receding famine" is the third pattern and it is one where many countries made great progress in reducing chronic hunger and famine and the consumption of fruits, vegetables and animal products increased. However, at this stage, physical activity levels started to decrease which could have been attributed to technological development. The fourth pattern "overeating and obesity related diseases" is characterized by diets that are high in fat, cholesterol, refined sugars, accompanied by sedentary lifestyles. This pattern is currently being observed all over the world especially in developing countries. Finally, is the behavior change pattern which describes behaviors similar to the first stage where there is increase in intake of fruits and vegetables and reduction in the consumption of refined carbohydrates. These changes are currently being observed mainly in developed countries as a response to increase in chronic diseases. Most of the work in nutrition transition mainly focuses on the fourth and fifth patterns.

For the African population, nutrition transition could be described following patterns three through five with most of the population quickly moving towards stage four (Popkin, 2004). As undernutrition and micronutrient deficiencies persist, overweight and obesity rates in African countries have shown a steady increase that has exceeded the prevalence of underweight since 1980 (Black et al., 2013). Shifts in dietary patterns have been mostly observed within the adult population, however, there are concerns that changes in infant and children feeding practices might soon shift to the young population as has been observed in developed countries.

Traditionally, the main types of food introduced to infants across Africa were plant based cereals made from mainly maize, sorghum, wheat or millet (Gibson, Ferguson, \& Lehrfeld, 1998). Although intake of cereal based complementary foods is usually associated with insufficient intakes of iron, calcium and zinc (Gibson et al., 1998), in some communities, amaranths, milk, soy, fish and edible termites are used to enrich cereal based foods (Konyole et al., 2012). With changing diets and improvement of social economic status among African families, infants are now introduced to foods high in fats and sugars as part of complementary foods (Popkin et al., 2012). These foods are energy dense instead of nutrient dense and research has shown that such foods may lead to adulthood diseases such as type 2 diabetes during childhood and later in adult life (Steyn \& McHiza, 2014). 


\section{Consequences of nutrition transition}

In general, nutrition transition affects everyone in the population regardless of age. The most common outcomes are chronic diseases such as diabetes and cardiovascular diseases (Delisle, Agueh, \& Fayomi, 2011). While the developed countries have the resources to deal with the rise in these conditions, African countries are still dealing with undernutrition especially in children which in itself exerts a lot of strain to the health care system in Africa (Salam et al., 2015).

Maternal malnutrition during pregnancy, inadequate breastfeeding and poor complementary feeding practices are associated with malnutrition in children. During pregnancy and lactation, nutrient needs increase making these periods nutritionally-vulnerable stages for women of child-bearing age (Khayat, Fanaei, \& Ghanbarzehi, 2017). Undernutrition in mothers is a cause for concern due to the impact adequate maternal nutrition has during the critical 1,000-day period from pregnancy to the first two years of the child's life (Woo Baidal et al., 2016). Similarly, obesity during pregnancy has been associated with poor health outcomes of the pregnancy such as increased risk of caesarian delivery, childhood overweight and obesity, diabetes in later life for mothers and obesity in adolescence for the children (Poston, Harthoorn, \& van der Beek, 2011; Valsamakis, Kyriazi, Mouslech, Siristatidis, \& Mastorakos, 2015).

The immediate effect of poor nutrition during the early years of a child is morbidity and mortality and, delayed cognitive, social-emotional and motor development (da Cunha, Leite, \& de Almeida, 2015), While the long-term effects include impairment in, intellectual ability, work capacity, reproductive outcomes and overall health during adolescence and adulthood (da Cunha et al., 2015). Infants born to undernourished mothers are likely to be undernourished as well at birth and if they experience rapid weight gain in childhood, they are much more likely to suffer from diabetes and cardiovascular diseases later in life than children who were not undernourished at birth (Victora et al., 2008). This means that in developing countries such as sub-Saharan Africa, greater efforts should be directed towards minimizing rapid dietary shifts towards consumption of high energy dense foods by children to mitigate possible development of chronic diseases in future life.

\section{Opportunities to slow nutrition transition in Africa}

Nutrition transition is inevitable as countries continue to expand their infrastructure and economic development. However, there are ways that the society can be more vigilant in order to slow down the progression. Many countries globally are working towards behavior change so that people can move from consumption of highly processed energy dense foods to increased intake of fruits and vegetables. However, in Africa there are communities, still experiencing famine, consuming diets high in fruits, vegetables and whole grains, and those that have adapted more westernized diets. This means that when planning interventions to slow down nutrition transition, these three levels should be considered. Interventions are needed to improve food production for those experiencing famine, nutrition education on the importance of maintaining traditional African diets are needed for those who are still consuming diets high in fruits, vegetables and whole grains and behavior modification interventions are needed for those who have adopted a more westernized diet.

\section{Education}

One avenue that nutrition and health related information is shared is through the formal schooling system. Nutrition and health related programs that are offered through school platforms have been shown to improve the health and nutrition status of the poor and vulnerable children in low and middle income countries (Sarr et al., 2016). For example, school meal programs common among many African countries encourage children to go to school because of the promise of a meal (Alderman, Hoddinott, \& Kinsey, 2006). For the most part, foods served in schools are sourced from local farmers and local markets and are therefore more likely than not to include traditional African diets rich in vegetables and whole grains. However, as nutrition transition progresses, there is a possibility that foods offered in schools might change into a more westernized diet that is more convenient and cheaper for the schools.

In a school setting, nutrition education can benefit the children, teachers as well as staff by providing them with the tools for healthy eating. Including nutrition education in the school curriculum is could help slow down the effects of nutrition transition, however, it has to be sensitive to the African context. Nutrition education curricula need to be linked to locally grown foods, cultures and diversity as well as environmental sustainability. This means that examples used in instruction should be based on healthy foods that are locally available and accessible to the children instead of using examples of foods that are 
foreign to the community.

Some studies that have evaluated the impact of nutrition education in schools especially and have shown positive outcomes in the nutrition and health status of the students. However, these studies focus more on undernutrition and not overweight and obesity (Walsh, Dannhauser, \& Joubert, 2002). It is noteworthy that prevalence of overweight and obesity in children is still low in sub Saharan Africa and therefore could be the reason behind lack of obesity-based interventions. However, this makes it the ideal time to introduce nutrition education in the school curricula to minimize adoption of unhealthy dietary patterns among school going children.

\section{Research and policy}

Researchers and policymakers have an opportunity to work with individuals and communities in African countries to try and slow down the negative effects of nutrition transition especially on children. From the documented literature, it is evident that there are a number of intervention activities that focus on mitigating the effects of acute food shortage. These interventions are mainly funded by international donor agencies. The main challenge with donor agency funded interventions is that they tend to focus on the agency's key interests that might not entirely reflect the needs of the society. For instance, many UN agencies work in the dry areas to provide food aid in form of ready to eat formulas for severely malnourished children and food rations for the moderately malnourished children. While this is a noble cause that has been done over the years, the real cause of severe malnutrition, which is poverty and low productivity has not been adequately addressed. Therefore, a cycle develops whereby malnourished children are rehabilitated but when they are out of danger, they fall back into the malnourished state due to the conditions that initially made them malnourished. In addition, most of the international donor agencies are very unlikely to engage in behavior change interventions that are needed for slowing down the effects of nutrition transition.

To effectively address nutrition transition, stakeholders need to work with communities to ensure that the magnitude and severity of adopting a western lifestyle are understood by the community members. To that end, there are a number of questions about people's perception of the changing nutrition status and dietary intake that need to be evaluated. For example, 1) How do individuals in African settings perceive consumption of westernized diets high in refined sugar and fat as compared to consumption of traditional diets high in fruits and vegetables and whole grains? 2) How does the community view overweight and obesity either in a child or an adult? 3) Are community members educated on the dangers of overweight and obesity that result from high calorie intake with sedentary behavior? 4) What are African governments doing to ensure that overweight and obesity do not reach alarming levels as those being witnessed in some of the developed countries? Some of these questions have been explored to some extent. For example in South Africa, a qualitative study among children found that some teenagers perceived being overweight and obese to be desirable especially by parents because it was an indication of happiness (Puoane, Tsolekile, \& Steyn, 2010). Another study found that being underweight might be perceived as suffering from HIV or AIDS hence undesirable (Okop, Mukumbang, Mathole, Levitt, \& Puoane, 2016). Such feedback indicates that before beginning a behavior modification intervention, education is needed to discount some of those beliefs and come up with mutually acceptable interventions. Also, some countries have developed policy documents that are geared towards curbing the increase in overweight and obesity. However, evaluation of such policies needs to be done.

\section{Conclusion}

There is sufficient documentation on nutrition transition in African countries. Consequences of nutrition transition are more severe in African countries than in developed countries as they pose a double burden of undernutrition and obesity to the community, households and individuals. Children in such households end up with developmental challenges and are more likely to develop adult diseases such as type 2 diabetes in childhood. Very few studies investigate the understanding and perception of individuals and communities towards the components of nutrition transition such as increase in energy intakeor increase in adiposity. Such studies are important because it is sometimes perceived that consumption of western diets and being overweight or obese are a sign of improved social economic status. This, therefore, may hinder government and other stakeholders' efforts towards slowing down the effects of nutrition transition. There are opportunities to slow down the effects of nutrition transition through education, policy and research. Food and nutrition topics that emphasize on consumption of traditional African diets and discourage the consumption of 
western diets could be introduced into the schools' curriculum. At policy level, national programs aimed at reducing hunger and malnutrition could focus more on ensuring intake of nutritious foods that are culturally appropriate and locally grown where possible.

\section{References}

Abrahams, Z., McHiza, Z., \& Steyn, N. P. (2011). Diet and mortality rates in Sub-Saharan Africa: Stages in the nutrition transition. BMC Public Health, 11, 12. doi:10.1186/1471-2458-11-801

Albala, C., Vio, F., Kain, J., \& Uauy, R. (2002). Nutrition transition in Chile: Determinants and consequences. Public Health Nutrition, 5(1A), 123128. doi:10.1079/phn2001283

Alderman, H., Hoddinott, J., \& Kinsey, B. (2006). Long term consequences of early childhood malnutrition. Oxford Economic Papers, 58(3), 450-474.

Allender, S., \& Rayner, M. (2007). The burden of overweight and obesity-related ill health in the UK. Obesity Reviews, 8(5), 467-473. doi:10.1111/j.1467789X.2007.00394.X

Bain, L. E., Awah, P. K., Geraldine, N., Kindong, N. P., Siga, Y., Bernard, N., \& Tanjeko, A. T. (2013). Malnutrition in Sub-Saharan Africa: Burden, causes and prospects. Pan African Medical Journal, 15(1).

Black, R. E., Victora, C. G., Walker, S. P., Bhutta, Z. A., Christian, P., de Onis, M., ... Uauy, R. (2013). Maternal and child undernutrition and overweight in low-income and middle-income countries. The Lancet, 382(9890), 427-451. doi:https://doi. org/10.1016/S0140-6736(13)60937-X

Bosu, W. K. (2015). An overview of the nutrition transition in West Africa: implications for noncommunicable diseases. Proceedings of the Nutrition Society, 74(4), 466-477.

da Cunha, A. J. L. A., Leite, Á. J. M., \& de Almeida, I. S. (2015). The pediatrician's role in the first thousand days of the child: The pursuit of healthy nutrition and development. Jornal de Pediatria, 91(6, Supplement 1), S44-S51.doi:https://doi. org/10.1016/j.jped.2015.07. 002

Delisle, H., Agueh, V., \& Fayomi, B. (2011). Partnership research on nutrition transition and chronic diseases in West Africa - trends, outcomes and impacts. BMC International Health and Human Rights, 11 Suppl 2(Suppl 2), S10. doi:10.1186/1472698x-11-s2-s10
Gibson, R. S., Ferguson, E. L., \& Lehrfeld, J. (1998). Complementary foods for infant feeding in developing countries: Their nutrient adequacy and improvement. European Journal of Clinical Nutrition, 52(10), 764-770. doi:10.1038/ sj.ejcn. 1600645

Khayat, S., Fanaei, H., \& Ghanbarzehi, A. (2017). Minerals in pregnancy and lactation: A review article. Journal of Clinical and Diagnostic Research, 11(9), Qe01-qe05. doi:10.7860/ jcdr $/ 2017 / 28485.10626$

Konyole, S. O., Kinyuru, J. N., Owuor, B. O., Kenji, G. M., Onyango, C. A., Estambale, B. B., ... \& Owino, V. O. (2012). Acceptability of amaranth grain-based nutritious complementary foods with dagaa fish (Rastrineobola argentea) and edible termites (Macrotermes subhylanus) compared to corn soy blend plus among young children/mothers dyads in western Kenya. Journal of Food Research, 1(3), 111.

Okop, K. J., Mukumbang, F. C., Mathole, T., Levitt, N., \& Puoane, T. (2016). Perceptions of body size, obesity threat and the willingness to lose weight among black South African adults: A qualitative study. BMC Public Health, 16, 365. doi:10.1186/s12889-0163028-7

Popkin, B. M. (1994). The nutrition transition in lowincome countries: an emerging crisis. Nutrition Reviews, 52(9), 285-298.

Popkin, B. M. (2004). The nutrition transition: An overview of world patterns of change. Nutrition Reviews, 62(7 Pt 2), S140-143.

Popkin, B. M., Adair, L. S., \& Ng, S. W. (2012). Global nutrition transition and the pandemic of obesity in developing countries. Nutrition Reviews, 70(1), 3-21. doi:10.1111/j.1753-4887.2011.00456.x

Poston, L., Harthoorn, L. F., \& van der Beek, E. M. (2011). Obesity in pregnancy: Implications for the mother and lifelong health of the child. A consensus statement. Pediatric Research, 69, 175. doi:10.1203/PDR.0b013e3182055ede

Puoane, T., Tsolekile, L., \& Steyn, N. (2010). Perceptions about body image and sizes among Black African girls living in Cape Town. Ethnicity and Disease, 20(1), 29-34. 
Salam, R. A., Syed, B., Syed, S., Das, J. K., Zagre, N. M., Rayco-Solon, P., \& Bhutta, Z. A. (2015). Maternal nutrition: How is Eastern and Southern Africa faring and what needs to be done? African Health Science, 15(2), 532-545. doi:10.4314/ahs.v15i2.28

Sarr, B., Fernandes, M., Banham, L., Bundy, D., Gillespie, A., McMahon, B., ... Drake, L. (2016). The evolution of school health and nutrition in the education sector 2000-2015 in Sub-Saharan Africa. Frontiers in Public Health, 4, 271. doi:10.3389/ fpubh.2016.00271

Stein, A. J. (2010). Global impacts of human mineral malnutrition. Plant and Soil, 335(1-2), 133-154. doi:10.1007/s11104-009-0228-2

Steyn, N. P., \& McHiza, Z. J. (2014). Obesity and the nutrition transition in Sub-Saharan Africa. Annals of the New York Academy of Sciences, 1311, 88-101. doi:10.1111/nyas.12433

Steyn, N. P., Nel, J. H., Parker, W., Ayah, R., \& Mbithe, D. (2012). Urbanisation and the nutrition transition: A comparison of diet and weight status of South African and Kenyan women. Scandinavian Journal of Public Health, 40(3), 229-238. doi:10.1177/1403494812443605

Tzioumis, E., Kay, M. C., Bentley, M. E., \& Adair, L. S. (2016). Prevalence and trends in the childhood dual burden of malnutrition in low- and middleincome countries, 1990-2012. Public Health Nutrition, 19(8), 1375-1388.
Valsamakis, G., Kyriazi, E. L., Mouslech, Z., Siristatidis, C., \& Mastorakos, G. (2015). Effect of maternal obesity on pregnancy outcomes and long-term metabolic consequences. Hormones, 14(3), 345-357.

Victora, C.G., Adair, L., Fall, C., et al, for the Maternal and Child Undernutrition Study Group. (2008). Maternal and child undernutrition: consequences for adult health and human capital. The Lancet, 371(9609), 340-357. doi:10.1016/s01406736(07)61692-4

Vorster, H. (2010). The link between poverty and malnutrition: A South African perspective. Health SA Gesondheid, 15(1).

Walsh, C. M., Dannhauser, A., \& Joubert, G. (2002). The impact of a nutrition education programme on the anthropometric nutritional status of low-income children in South Africa. Public Health Nutrition, 5(1), 3-9.

Woo Baidal, J. A., Locks, L. M., Cheng, E. R., Blake-Lamb, T. L., Perkins, M. E., \& Taveras, E. M. (2016). Risk factors for childhood obesity in the first 1,000 Days: A systematic review. American Journal of Preventive Medicine, 50(6), 761-779. doi: 10.1016/j. amepre.2015.11.012

\section{Authors}

${ }^{1}$ Teresia Mbogori (tnmbogori@bsu.edu) is an Assistant Professor in the Department of Nutrition and Health Sciences at Ball State University, Muncie, Indiana, USA.

${ }^{2}$ Winnie Mucherah (wmucherah@bsu.edu) is a Professor in the Department of Educational Psychology at Ball State University, Muncie, Indiana, USA. 